\title{
Influence of Extracellular Matrix on the Proliferation and Differentiation of Glioma Cells in Culture
}

\author{
Masashi TAKAGI, Hajime SUgIHARA* and Kazuo TABUCHI \\ Departments of Neurosurgery and *Pathology, Saga Medical School, Saga
}

\begin{abstract}
The influence of extracellular matrix on the proliferation and differentiation of glioma cells in vitro was investigated by culturing glioma cells in collagen gel and on collagen and laminin films. Rat C-6 glioma cells extended thin cytoplasmic processes, proliferated, and differentiated in collagen gel and on collagen film. The cells were stellate with multiple thin processes like the astrocyte in vivo. The intracellular content of cyclic adenosine-monophosphate in rat C-6 glioma cells on collagen film increased approximately four fold over the control level. In laminin film culture, rat C-6 glioma cells extended thin cytoplasmic processes with many knotty structures and proliferated. These findings confirm that extracellular matrix induces the differentiation of glioma cells.
\end{abstract}

Key words: glioma, extracellular matrix, collagen, laminin, cyclic adenosine-monophosphate

\section{Introduction}

Extracellular matrix is the basic structural component of tissue. It surrounds the cells in vivo and influences cellular proliferation and differentiation. Recent studies indicate that extracellular matrix components, especially collagen, participate in cellular proliferation and differentiation. ${ }^{3,8,20)}$ Myoblasts differentiate into muscle fibers in collagen film culture. ${ }^{\text {s) }}$ Mammary epithelial cells produced milk proteins in collagen gel culture in the presence of related hormones. ${ }^{4,19)} \mathrm{We}$ found that mature fat cells in collagen gel culture proliferate and maintain cell functions. ${ }^{15 j}$ The extracellular matrix in the central nervous system (CNS) is closely associated with important cellular functions, such as proliferation, differentiation, and migration of neural cells. ${ }^{2,18}$ Rutka et al. ${ }^{12)}$ showed that the collagen component in extracellular matrix significantly influenced the proliferation and differentiation of glial tumor cells in vitro.

Astrocytes in brain tissue extend multiple thin cytoplasmic processes to form complex networks around the capillary basement membrane, which is mainly collagen and laminin. The blood-brain barrier is a combination of capillaries and astrocyte foot processes. Glioma cells around blood vessels

Received June 14, 1990; Accepted January 16, 1991 demonstrate intense immunohistochemical staining for glial fibrillary acidic protein. This suggests that the extracellular matrix around local blood vessels causes glioma cells to differentiate. ${ }^{11)}$ However, it is not clear how the CNS extracellular matrix influences the proliferation and differentiation of glial or glioma cells. Here, we investigated the proliferation and differentiation of cultured glioma cells in an extracellular matrix.

\section{Materials and Methods}

\section{Cell cultures}

Rat $\mathrm{C}-6^{17}$ and human KC-P $14^{17}$ glioma clonal cell lines were maintained in monolayer cultures on 65 mm plastic dishes under standard tissue culture conditions $\left(37^{\circ} \mathrm{C}\right.$, under $5 \% \mathrm{CO}_{2}, 95 \%$ air) on Eagle's minimum essential medium (MEM) supplemented with $10 \%$ fetal calf serum and gentamycin. The rat C-6 glioma cells maintained S-100 protein immunoactivity over serial passages. Human $\mathrm{KC}-\mathrm{P} 14$ glioma cells were derived from a 40-year-old female with a glioblastoma (Prof. A. Nishimoto, Okayama University Medical School, Okayama).

Monolayer culture: The monolayer cell cultures had a concentration of $5 \times 10^{3}$ cells $/ \mathrm{cm}^{2}$ in a $35 \mathrm{~mm}$ plastic dish.

Collagen, laminin, and fibronectin film cultures: Collagen solution (types I, III, and IV; Nitta Gelatin Co., Ltd., Yao, Osaka) was diluted 1:10 with dis- 

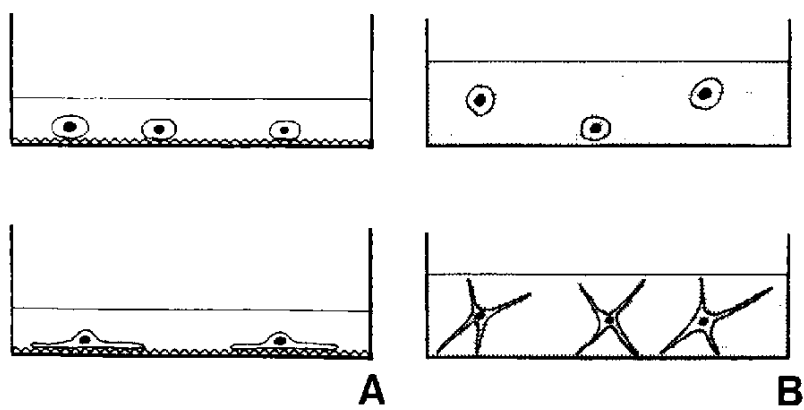

Fig. 1 A: Isolated glioma cells were plated on extracellular matrix (upper). Some rat C-6 glioma cells extended thin cell processes and proliferated 12 hours after plating on collagen or laminin film (lower). B: Isolated glioma cells were embedded in collagen gel (upper). The glioma cells extended thin processes multidirectionally and proliferated 12 hours after embedding (lower).

tilled water. Laminin (Nitta Gelatin Co., Ltd.) and fibronectin (Organon Teknika Corp.-Cappl Products, West Chester, U.S.A.) were diluted 1:10 with phosphate-buffered saline containing no calcium or magnesium [PBS $(-)]$. The surfaces of culture dishes were coated with these solutions. After drying at $4^{\circ} \mathrm{C}$, the dishes were washed five times with PBS(-). Cell suspensions were cultured in these dishes (Fig. 1A).

Collagen gel culture: We used the Elsdale and Bard procedure ${ }^{3)}$ as modified by Enami et al. ${ }^{4)}$ Briefly, eight volumes of acid-soluble type I collagen solution were mixed with one volume of $10 \times$ concentrated Eagle's MEM and one volume of reconstruction buffer (2.2 gm $\mathrm{NaHCO}_{3}, 4.77 \mathrm{gm} \mathrm{N}$-2-hydroxyethylpiperazine-N'-2-ethanesulfonic acid, $100 \mathrm{ml}$ $0.05 \mathrm{~N} \mathrm{NaOH}$ ). This mixture cooled in ice was mixed with separated glioma cells. Cell mixture $(2 \mathrm{ml})$ containing $5 \times 10^{4}$ cells $/ \mathrm{ml}$ was placed in a $35 \mathrm{~mm}$ culture dish and immediately warmed to $37^{\circ} \mathrm{C}$ to form a gel. After 30 minutes, when the gel had sufficient strength, a coating of medium $2 \mathrm{ml} /$ dish was formed (Fig. 1B).

Soft agar gel culture: Soft agar (Agar noble; DIFCO Laboratories, Detroit, Michigan, U.S.A.) was dissolved in distilled water to form a $1 \%$ solution. This was autoclaved for 15 minutes, then kept at $60^{\circ} \mathrm{C}$. One volume of this solution was mixed with one volume of $2.25 \times$ concentrated Eagle's MEM supplemented with $20 \%$ fetal calf serum. Two volumes of this mixture were mixed with one volume of the prepared cell suspension $\left(5 \times 10^{4}\right.$ cells $/ \mathrm{ml}$ ) at $37^{\circ} \mathrm{C}$.

\section{Examination of cell cultures}

Immunohistochemistry for S-100 protein: Rat C-6 glioma cells cultured on collagen film were fixed with methanol and ethanol $(1: 1)$ at $4^{\circ} \mathrm{C}$ for 10 minutes, reacted with a 1:200 dilution of mouse anti-S-100 protein (Cosmo Bio., Tokyo) primary antibody for 30 minutes, then rinsed with $\mathrm{PBS}(-)$. The resultant cells were used for immunohistochemical testing by the avidin-biotin-peroxidase complex method, and staining with diaminobenzidine (Sigma, St. Louis, Mo., U.S.A.).

Immunohistochemistry for tubulin: Cells cultured on collagen film were fixed with $2 \%$ paraformaldehyde at $4^{\circ} \mathrm{C}$ for 1 minute and acetone $\left(-20^{\circ} \mathrm{C}\right)$ for 15 minutes. A 1:500 dilution of mouse anti-tubulin primary antibody (Amersham, Buckinghamshire, England) was applied for 1 hour, followed by staining with fluorescein isothiocyanate conjugated rabbit anti-mouse immunoglobulin G (IgG).

Bromodeoxyuridine (BrdU) labeling: BrdU was added to the cell culture for 2 hours. The cells were then fixed with acidic ethanol for 15 minutes, and reacted with anti-BrdU antibody (Amersham) for 1 hour, then rinsed with PBS( - ). The culture was then reacted with anti-mouse IgG by the indirect immunohistochemical method, and stained with diaminobenzidine. Hematoxylin and eosin stains were performed last.

\section{Cyclic adenosine-monophosphate (cAMP) as- say in cells}

The cAMP content in cells was assayed in the normal monolayer and collagen film cultures. Duplicate control and collagen-coated $35 \mathrm{~mm}$ dishes were inoculated with $1 \times 10^{6}$ glioma cells. After 24hour culture, the cAMP content in the cells were measured by the radioimmunoassay method. ${ }^{6}$

\section{Effect of N-2'-dibutyryl adenosine-3'-5'-cyclic monophosphate Na-salt (db-cAMP)}

Normal monolayer and collagen film cell cultures were plated on dishes. Six hours later, db-cAMP (Seikagaku-kogyo, Tokyo) was added at final concentrations of $0.1-1 \mathrm{mM}$ to the mediums.

\section{Results}

\section{Cell cultures}

Usual monolayer culture: Monolayer rat C-6 glioma cells on a plastic dish proliferated extensively and became confluent within 4-5 days. The cells were short spindle-shaped and bipolar with short processes (Fig. 2A). Human KC-P14 glioma cells proliferated and became confluent within 3 days. The 


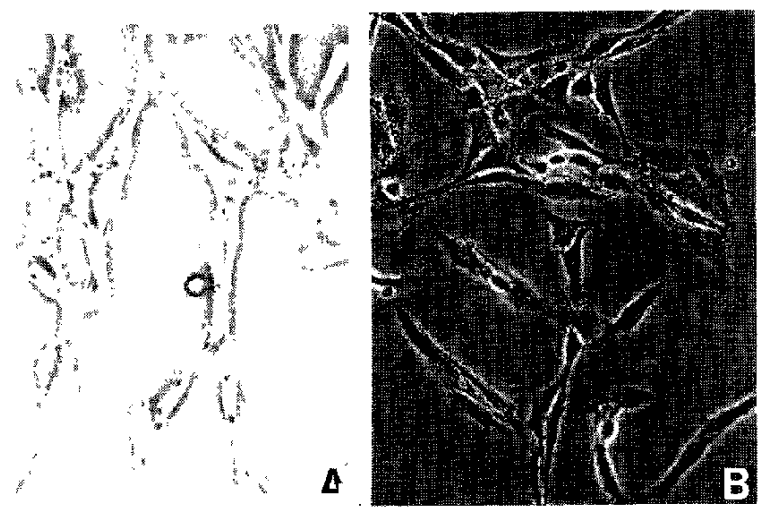

Fig. 2 A: Rat C-6 glioma cells on usual plastic dish proliferated extensively in a monolayer. Cells are short spindle-shaped and bipolar with short processes. $\times 200$. B: Human KC-P14 glioma cells on usual plastic dish proliferated in a monolayer. Cells are rectangular without obvious processes. $\times 200$. cells were rectangular without obvious processes (Fig. 2B).

Collagen, laminin, and fibronectin film cultures: In type I collagen film culture, $20-30 \%$ of rat C-6 glioma cells extended thin cell processes 12 hours after plating. The cells were stellate and extended multiple thin processes like the astrocyte in vivo (Fig. 3A). The processes stained positively for S-100 protein by the immunohistochemical technique (Fig. 3B). Tubulin immunostaining revealed an intracytoplasmic network (Fig. 3C). The cells were apparently morphologically differentiated, but cell divisions were also observed. Rat C-6 glioma cells were positive to BrdU labeling in the presence and absence of differentiation, with labeling indices of 2.5 and $3.1 \%$, respectively. There was no significant difference. In type III or IV collagen film culture, similar morphological changes were observed, but to lesser extents (Table 1). Human KC-P14 glioma cells extended thin processes multidirectionally, but had shorter processes than rat C-6 glioma cells. The cells proliferated.

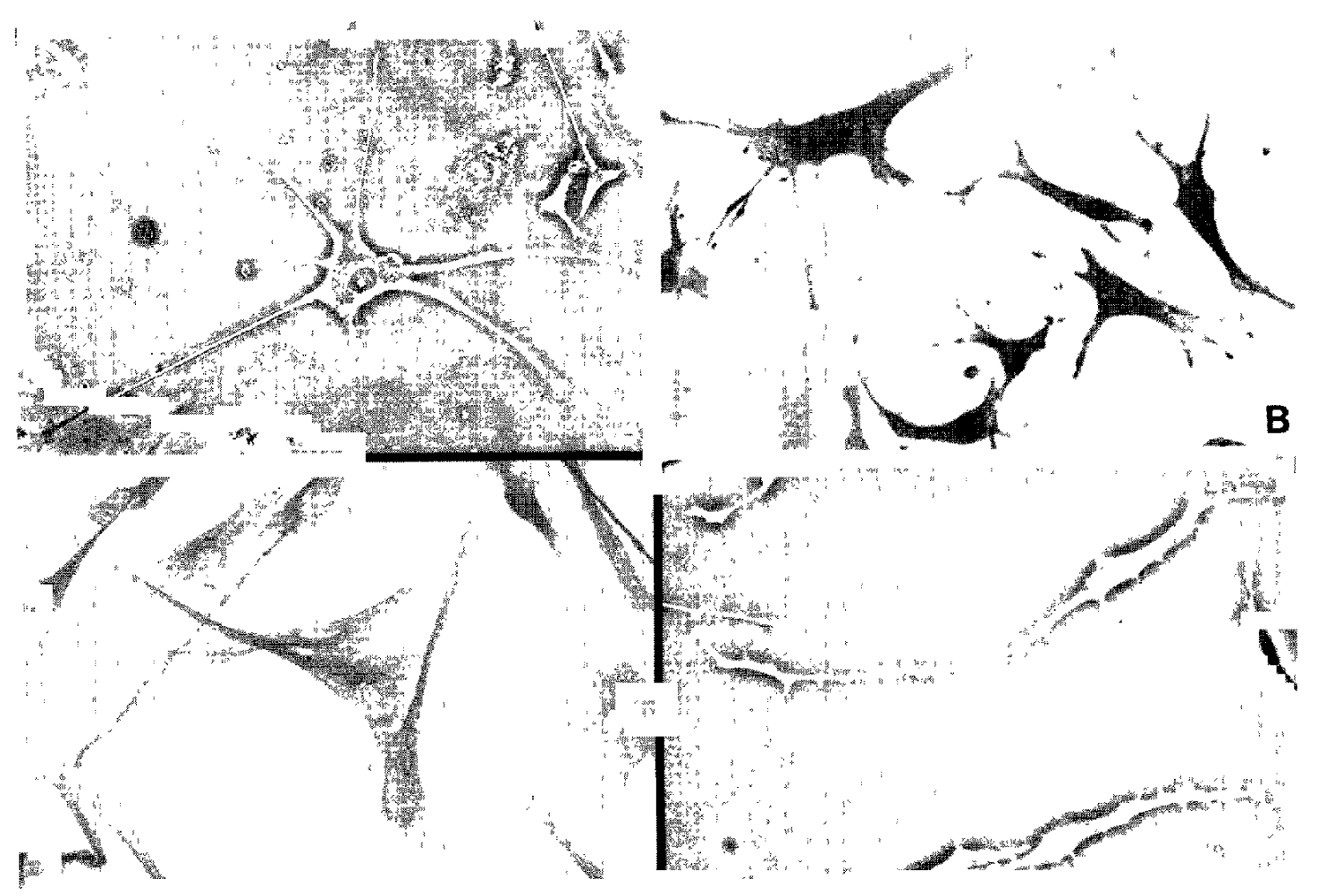

Fig. 3 A-C: Rat C-6 glioma cells in collagen film culture. Cells extend thin cell processes and are stellate in form like the astrocyte in vivo (A). Cell processes are positively immunostained for S-100 protein (B). A network of intracytoplasmic filaments of microtubules is seen (C). $\times 300 . \quad$ D: Rat C6 glioma cells in laminin film culture. Cells extend long processes, which are bipolar with many knotty structures. $\times 430$. 
Table 1 Effect of different environments on the differentiation and proliferation of rat C-6 glioma cells

\begin{tabular}{|c|c|c|c|c|c|c|c|}
\hline & \multirow{2}{*}{$\begin{array}{l}\text { Usual monolayer } \\
\text { culture }\end{array}$} & \multirow{2}{*}{$\frac{\text { Collagen }}{\text { Type I }}$} & film culture & \multirow{2}{*}{$\begin{array}{l}\text { Collagen gel } \\
\text { culture }\end{array}$} & \multirow{2}{*}{$\begin{array}{l}\text { Laminin film } \\
\text { culture }\end{array}$} & \multirow{2}{*}{$\begin{array}{l}\text { Fibronectin } \\
\text { film culture }\end{array}$} & \multirow{2}{*}{$\begin{array}{l}\text { Addition of } \\
\text { db-cAMP }\end{array}$} \\
\hline & & & III & & & & \\
\hline Thin process & 0 & ++ & + & ++ & + & 0 & +++ \\
\hline Proliferation & 0 & 0 & + & 0 & 0 & 0 & - \\
\hline
\end{tabular}

$-:$ inhibition, 0 : no effect, $+:$ mild effect, ++ : moderate effect, +++ : severe effect.

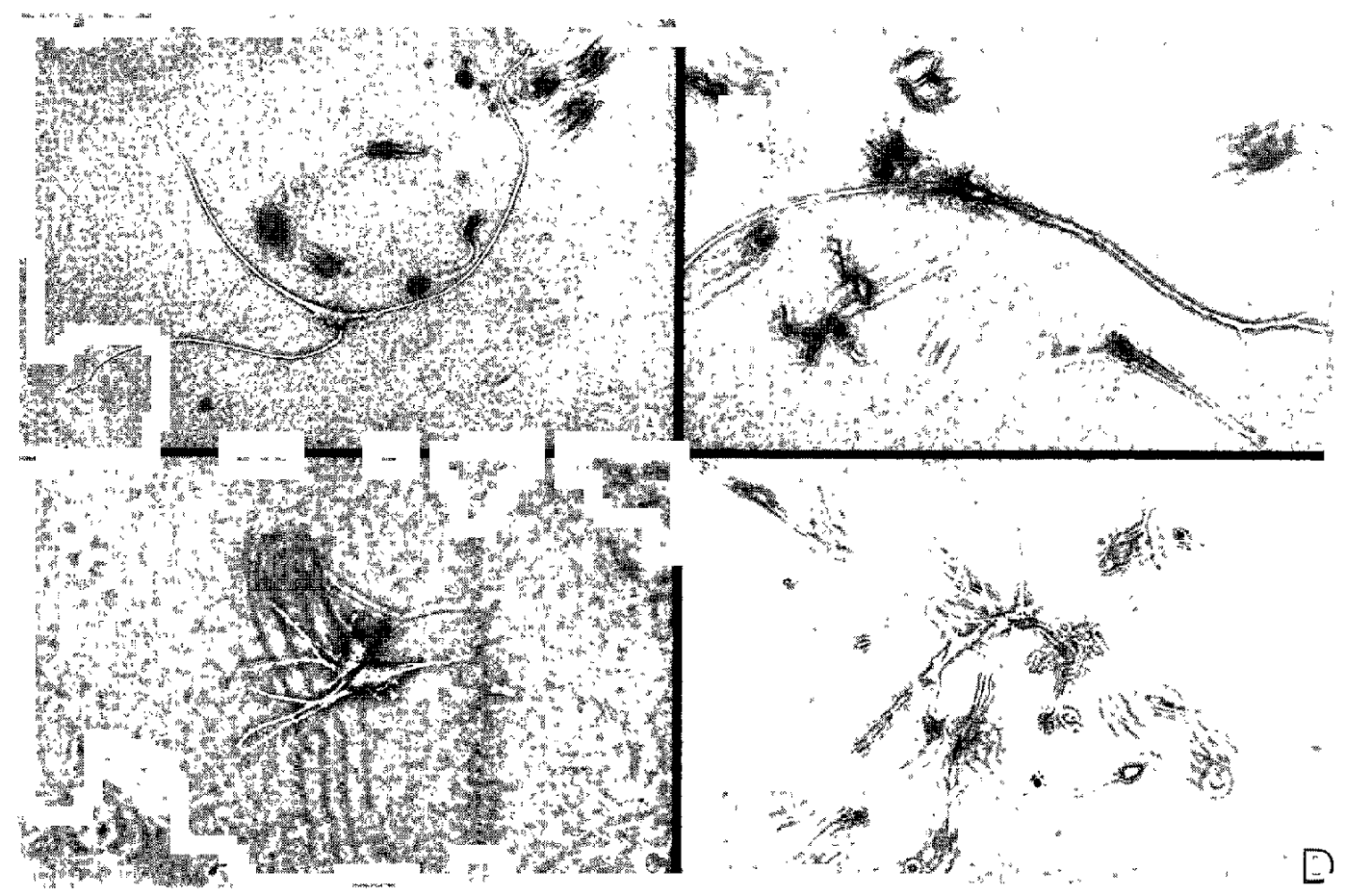

Fig. 4 A-C: Rat C-6 glioma cells in collagen gel culture. Background, collagen gel. Cells extend thin processes multidirectionally (A). Some processes are branched (B). Cell divisions and proliferations are observed (C). A, $\times 200$; B and C, $\times 300$. D: Human KC-P14 glioma cells in collagen gel culture. Cells extend similar cell processes and proliferate. $\times 300$.

In laminin film culture, $30-40 \%$ of rat C-6 glioma cells extended long processes. The processes were bipolar and had many knotty structures (Fig. 3D). No inhibition of proliferation was observed. Human KC-P14 glioma cells underwent no morphological change and proliferation was not inhibited.

In fibronectin film culture, neither rat $\mathrm{C}-6$ nor human KC-P14 glioma cells showed morphological changes and neither was inhibited from proliferation.

Collagen gel culture: In the collagen gel culture, more than $90 \%$ of rat C- 6 glioma cells extended thin processes 12 hours after embedding. The processes were five to ten times longer than the cell bodies. Three to four processes were extended multidirec- tionally from each cell body (Fig. 4A) and grew. branches (Fig. 4B). Morphologically, they were as differentiated as those of astrocytes. However, there was distinct evidence of cell divisions and no inhibited proliferation (Figs. 4C and 5). Human KCP14 glioma cells extended similar cell processes, but these were shorter (Fig. 4D). The human glioma cells also proliferated.

Soft agar gel culture: In soft agar gel culture, rat C-6 glioma cells were round, proliferated, and formed colonies, but did not extend cell processes.

\section{II. cAMP assay in cells}

The content of cAMP in rat C-6 glioma cells in collagen film culture was approximately four times that 


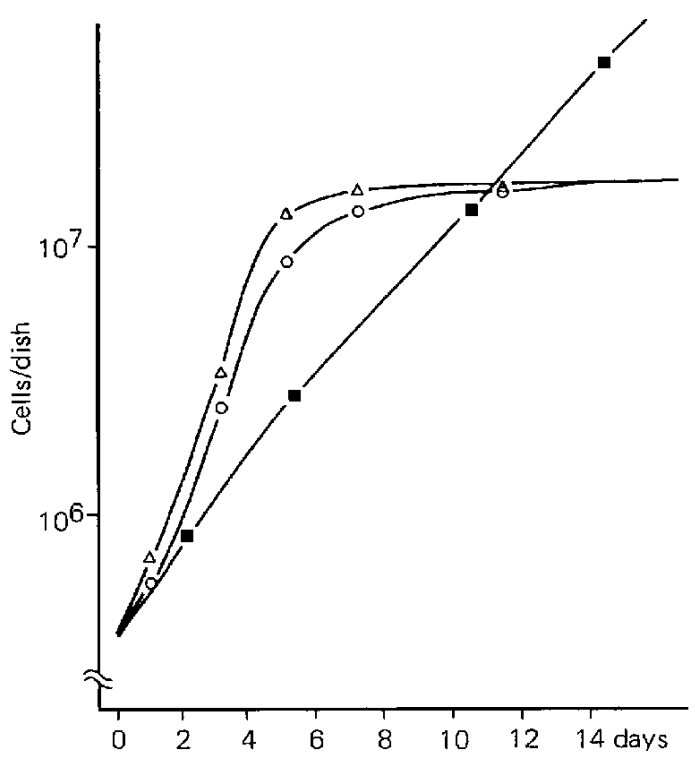

Fig. 5 Growth curves for rat C-6 glioma cells. Cells in normal monolayer $(O)$ and collagen film cultures $(\triangle)$ proliferate similarly to in collagen gel culture ( $\mathbf{\square})$.

in control cells in the normal monolayer culture 24 hours after plating.

\section{Effect of db-cAMP}

In the normal monolayer and collagen film cultures, more than $30 \%$ of rat C- 6 glioma cells extended extremely slender processes multidirectionally 12 hours after addition of $1 \mathrm{mM}$ db-cAMP. The processes were longer than in the collagen film culture. Moreover, they were richly long-branched. There was no obvious morphological difference between the glioma cells treated with db-cAMP in the normal monolayer and the collagen film cultures. In the normal monolayer culture, proliferation was inhibited by db-cAMP. The morphological changes and the inhibition of proliferation were reversible by removal of db-cAMP from the medium. No morphological changes were caused by $0.1 \mathrm{mM}$ dbcAMP. Human KC-P14 glioma cells extended similar processes and proliferation was inhibited by $1 \mathrm{mM}$ db-cAMP.

\section{Discussion}

In the CNS, extracellular matrix is present as the basement membrane between the astrocyte foot processes and the capillary endothelial cells. ${ }^{2,14)}$ The collagen component of extracellular matrix inhibits the proliferation and induces the differentiation of glioma cells. ${ }^{12)}$ Laminin formation by immature rat astrocytes in primary culture suggests that laminin is important in CNS development.9" However, the precise function of the extracellular matrix in the CNS is not yet fully understood.

We found that collagen induced rat $\mathrm{C}-6$ and human KC-P14 glioma cells to develop thin cytoplasmic processes multidirectionally. There was no morphological difference of glioma cells in either collagen film or gel cultures except for the development of cytoplasmic processes. These cells were morphologically differentiated. In a soft agar gel culture, rat glioma cells showed no morphological change. These findings confirm that collagen induces morphological differentiation in glioma cells. The network of thin intracytoplasmic filaments positively stained for S-100 protein by immunohistochemical techniques.

The cAMP content of rat C-6 glioma cells in collagen film culture increased approximately four fold over the control and was associated with morphological changes. It is well known that cAMP is closely associated with cellular differentiation and functions. Previous work suggests that the intracellular cAMP content of undifferentiated glial cells is lower than that of differentiated cells. ${ }^{10)}$ Our result confirms this.

In this study, db-cAMP induced both rat C-6 and human KC-P14 glioma cells to differentiate morphologically and also inhibited proliferation. Cultured glioma cells differentiate morphologically in the presence of cAMP, and proliferation is inhibited. ${ }^{16)}$ However, both proliferation and morphological differentiation in human medulloblastoma cell lines are dependent on the db-cAMP concentration. ${ }^{13)}$ We found that in collagen matrix and film cultures, glioma cells proliferated and morphologically differentiated. We cannot definitively explain this phenomenon. However, the stimulation mechanism of collagen is different from that of dbcAMP, so in collagen film or gel glioma may both proliferate and differentiate.

We found that rat C-6 glioma showed morphological differentiation but proliferation was not inhibited in type I, III, or IV collagen film culture. In contrast, Rutka et al. ${ }^{12)}$ reported that on type I or IV collagen-coated flasks, glioma cells showed similar morphological changes but were inhibited from proliferation. We also found that glioma cells developed many knotty structures on cytoplasmic processes in laminin film culture, a previously unreported result.

It is not known how collagen induces morphological differentiation in glioma cells. Recently, receptors specific to the extracellular matrix in 
various normal or tumor cells have been proposed." Our result supports this hypothesis of a specific collagen receptor on the glioma cell membrane. We infer that increased intracellular cAMP caused by stimulation of collagen receptors induces cellular differentiation.

Astrocytes form the blood-brain barrier in vivo with multiple thin cytoplasmic processes extending to the capillary basement membrane. In contrast, glioma cells in vivo have only two or three short processes. These processes do not adhere to the basement membrane, so glioma cells cannot form the blood-brain barrier. We found that glioma cells extended multiple thin processes and demonstrated branching in the presence of collagen. These structures resemble the multiple thin cytoplasmic processes of astrocytes in vivo. We suggest that a coculture of glioma cells and endothelial cells will help elucidate the development of the blood-brain barrier.

\section{Acknowledgments}

We wish to thank Mr. K. Ideguchi, Miss Y. Saho, and Mrs. C. Ideguchi for technical assistance, Prof. K. Tohkaichi, Department of English, Saga Medical School, for editing the English text, and Dr. S. Miyabara and Prof. T. Watanabe, Department of Pathology, Saga Medical School, for their helpful advice.

\section{References}

1) Benda P, Lightbody J, Sato G, Levine L, Sweet W: Differential rat glial cell strain in tissue culture. Science 161: 370-371, 1968

2) Carbonetto $S$ : The extra cellular matrix of the nervous system. Trends Neurosci 7: 382-387, 1984

3) Elsdale T, Bard J: Collagen substrate for studies on cell behavior. I Cell Biol 54: 626-637, 1972

4) Enami J, Koezuka M, Hata M, Enami S, Koga M: Gel strength-dependent branching morphogenesis of mouse mammary tumor cells in collagen gel matrix culture. Dokkyo J Med Sci 12: 25-30, 1985

5) Hauschka SD, Konigsberg IR: The influence of collagen on the development of muscle clones. Proc Nat Acad Sci USA 55: 119, 1966

6) Honma $M$, Satoh $T$, Takezawa $T$ : An ultrasensitive method for the simultaneous determination of cyclic AMP and cyclic GMP in small volume samples from blood and tissue. Biochem Med 18: 257-273, 1977

7) Hynes RO: A family of cell surface receptors. Cell 48: 549-554, 1987

8) Kleinman HK, Klebe RJ, Martin GR: Role of collagenous matrices in the adhesion and growth of cells. J Cell Biol 88: 473-485, 1981

9) Liesi P, Dahl D, Vaheri A: Laminin is produced by early rat astrocytes in primary culture. $J$ Cell Biol 96 : 920-924, 1983

10) Mathilda AF, Kenneth SD: Cyclic AMP and adenyl cyclase in brain tumors. $J$ Neurosurg 46: 477-483, 1977

11) Paulus W, Roggendorf W, Schuppan D: Immunohistochemical investigation of collagen subtypes in human glioblastoma. Virchows Arch [Pathol Anat] 413: 325-332, 1988

12) Rutka JT, Giblin JR, Apodaca G, DeArmond SJ, Stern R, Rosenblum ML: Inhibition of growth and induction of differentiation in a malignant human glioma cell line by normal leptomeningeal extracellular matrix proteins. Cancer Res 47: 35153522,1987

13) Sasaki F, Schneider SL, Zeltzer PM: Dibutyryl adenosine $3^{\prime}: 5^{\prime}$-cyclic monophosphate (db-cAMP) induced growth inhibition and morphologic changes in human medulloblastoma cell line TE671, in: Biology of Brain Tumour. Boston, Martinus Nijhoff, 1986, pp 27-34

14) Shellswell GB, Restall DJ, Duance VC, Bailey AJ: Identification and differential distribution of collagen types in the central and peripheral nervous systems. FEBS Lett 106: 305-308, 1979

15) Sugihara $H$, Yonemitsu $N$, Toda $S$, Miyabara $S$, Funatsumaru $\mathrm{S}$, Matsumoto $\mathrm{T}$ : Unilocular fat cells in three-dimensional collagen gel matrix culture. $J$ Lipid Res 29: 691-697, 1988

16) Tabuchi K, Furuta $T$, Norikane $H$, Tsuboi M, Moriya $Y$, Nishimoto A: Evaluation of the drug-induced morphological differentiation of rat glioma cells (C-6) from the aspects of S-100 protein level and con A binding pattern. J Neurol Sci 51: 119-130, 1981

17) Tabuchi $K$, Shiraishi T, Takagi M, Momosaki N, Mineta T: Cell kinetics analysis of brain tumors by means of BrdUrd, Ki-67 and PCNA. No Shuyo Byori 6: 157-160, 1989 (in Japanese)

18) Tomaselli KJ, Damsky CH, Reichardt LF: Interactions of a neuronal cell line (PC12) with laminin, collagen IV, and fibronectin: Identification of integrinrelated glycoproteins involved in attachment and process outgrowth. J Cell Biol 105: 2347-2358, 1987

19) Yang J, Guzman R, Richard J, Jentoff V, Devault $M R$, Wellings SR, Nandi S: Primary culture of human mammary epithelial cells embedded in collagen gel. JNCI 65: 337-343, 1980

20) Yang J, Nandi S: Growth of cultured cells using collagen as substrate. Int Rev Cytol 81: 249-286, 1983

Address reprint requests to: M. Takagi, M.D., Department of Neurosurgery, Saga Medical School, 5-1-1 Nabeshima, Nabeshima-machi, Saga 849, Japan. 